\title{
Isocyanate exposure and occupational asthma: a case-referent study
}

\author{
S K Meredith, J Bugler, R L Clark
}

\begin{abstract}
Objective-To examine the quantitative relation between exposure to isocyanates and occupational asthma, and to explore the role of atopy and smoking in occurrence of the disease.

Method-A case-referent study was undertaken of cases from two manufacturing companies ( $A$ and $B$ ) from which referents without disease could be selected and reliable exposure measurements were available. In company $A, 27$ cases mainly attributed to toluene diisocyanate (TDI) were matched to 51 referents on work area, start and duration of employment, sex, and age. Exposures were estimated from existing measurements by job category. In company $B$ there were seven cases attributed to 4,4'-diphenylmethane diisocyanate (MDI) in two areas of the plant; 12 non-cases from the same areas were used as referents. Personal exposure measurements were available for all cases and 11 referents.
\end{abstract}

Results-No difference in peak exposures between cases and referents was found in either plant; but in both, time weighted average (TWA) exposures at the time of onset of asthma were higher for cases. In $A$, the mean TWA exposure for cases was $1.5(95 \%$ confidence interval $(95 \%$ CI) 1.2 to 1.8$)$ ppb compared with 1.2 (1.0 to 1.4$)$ ppb for referents. From a matched analysis, the odds ratio $(O R)$ associated with 8 hour TWA exposure to isocyanates greater than $1.125 \mathrm{ppb}$ (the median concentration for the referent group) was 3.2 (95\% CI 0.96 to $10.6 ; p=0.06)$. Occupational asthma was associated with a pre-employment history of atopic illness (OR 3.5, p=0.04) and, less strongly, with smoking (OR 2.1, $p=0.14)$. In $B$, small numbers limited analysis, but three of seven cases had at least one TWA exposure measurement greater than 5 ppb compared with one of 11 referents (OR 7.5, p=0.09).

MRC Clinical Trials Unit, 222 Euston Road, London NW1 2DA, UK S K Meredith

Private addresses J Bugler R L Clark

Correspondence to: Dr S Meredith sm@ctu.mrc.ac.uk

Accepted 25 July 2000
Isocyanates are used in the manufacture of many products - such as flexible and rigid polyurethane foams, polyurethane rubbers, and elastomers - and are to be found as cross linking agents in specialty surface coatings, inks and adhesives, and binders for foundry cores. They are thus used in a great variety of industries. Isocyanates are also the most commonly identified cause of occupational asthma in most industrialised countries. In the United Kingdom, $17 \%$ of the cases of occupational asthma reported between 1989 and 1996 by consultant chest and occupational physicians to the surveillance of work related and occupational respiratory disease (SWORD) project, a national reporting scheme for occupational lung disease, were attributed to isocyanates. ${ }^{1}$ Also, isocyanates were the most common cause of occupational asthma for which disablement benefit was awarded in Great Britain in every year between 1991 and $1997 .^{2}$ Many of those affected continue to experience asthmatic symptoms even after removal from further exposure to isocyanate..$^{3-5}$ As well as being a cause of ill health, occupational asthma is also associated with loss of employment and income. ${ }^{67}$ The prevention of asthma due to exposure to isocyanates is therefore important.

The quantitative relation between intensity of exposure to isocyanates and the development of asthma is uncertain. The object of this study was to explore this relation and to examine the role of atopy and smoking in groups of cases of occupational asthma attributed to isocyanates reported to SWORD from the same workplace.

\section{Method}

A case-referent study was undertaken and used available contemporaneous exposure measurements to investigate the relation between exposure to isocyanates and the development of asthma.

\section{SELECTION OF CASES}

Occupational physicians who had reported to SWORD five or more cases of asthma attributed to isocyanates between 1989 and 1993 were contacted. The study was confined to cases reported by occupational physicians employed in industry so that controls from the same workplace could be selected and comparable data collected for both. There were four potential groups of cases for investigation. Group A consisted of 24 cases attributed to toluene diisocyanate (TDI) and three to 4,4'-diphenylmethane diisocyanate (MDI) from six factories of one company. The cases of TDI, with the exception of two which arose in 
factories involved in flame bonding and the surface coating of fabrics, occurred in the manufacture of moulded and block flexible polyurethane foam, an exothermic process that results in some release of TDI to the atmosphere. The cases of MDI were involved in the batch moulding of rigid polyurethane components (vehicle roof liners) at $200^{\circ} \mathrm{C}$. Group B consisted of seven cases attributed to MDI from a chemical plant in which MDI and polymeric MDI mixtures were processed and poured into drums. Some processes involved heating the mixtures. Group C consisted of 20 cases from three areas of a shipyard in which MDI based surface coatings and adhesives were applied in confined areas. Group D consisted of six cases in pipe layers who used MDI based jointing materials, often in confined spaces.

Company D closed its occupational health department before the investigation began and therefore could not be included in the study. Group C was also excluded because the environmental measurements available, which had been taken after the cases had come to light, were mainly static and did not permit differentiation of exposure between individual people working in the same area.

The occupational physicians for companies $\mathrm{A}$ and $\mathrm{B}$ completed a questionnaire for each case which requested information on the timing of onset of asthma symptoms and diagnosis, the basis on which the diagnosis was made, and the subject's job title and work area at the time symptoms were first noted. There was pre-employment health screening and occupational health surveillance in both companies. In company $A$, surveillance included a respiratory symptom questionnaire and lung function testing that was carried out before employment, at 3 weeks, 6 weeks and 3 months after starting work, and subsequently every 6 months throughout employment. Anyone who developed respiratory symptoms was subject to investigation with serial peak flow measurements four times daily until a diagnosis was established. Subjects were usually removed from exposure to isocyanates until their initial symptoms resolved. They were then allowed to return to areas within the workplace where the isocyanate concentrations were known to be low, under close supervision. If there was no evidence of recurrence of symptoms, a gradual return to the previous employment was permitted. In practical terms, therefore, affected people were subject to a very gradual challenge test to the workplace environment, sometimes lasting for several months, until it had been established to the satisfaction of the supervising occupational physician that respiratory symptoms were or were not occupationally related.

In 29 of the 34 cases ( 25 from company A and four from company B), occupational asthma was diagnosed from a history of recurrent work related respiratory symptoms, with a pattern of improvement on days away from work, together with serial respiratory function testing with spirometry or peak flow measurements. In one case from company $\mathrm{B}$ specific $\mathrm{IgE}$ was detected and the remaining four cases (two from each site) were diagnosed on the basis of history alone.

SELECTION OF REFERENTS

The occupational health physician at each site was asked to provide a list of potential controls. These were defined as people without asthma, of the same sex as the case, who were working in the same area, both at the time the case started the job in which he developed asthma and when the diagnosis of occupational asthma was made. It was planned to select at least one, and if possible two, referents for each case on the basis of closeness in age and dates of employment. On these criteria, 51 referents were identified for the 27 cases from company A.

At company B it was not possible to match controls as planned. The seven cases came from two areas of the plant with a workforce of only 23 people during the relevant period. Because many of the subjects had moved between the two areas, matching on work area was not possible. Also, because of the few workers from whom to select referents, the matching on the other factors would be poor. Therefore an unmatched approach was taken, with all non-cases as a basis for comparison. Of the 16 potential referents from company B (the total number of workers in the two areas, excluding the seven cases), employment and medical records were not found for two, who therefore could not be included in the study. A further two had developed adult onset asthma diagnosed by a chest physician as nonoccupational. They were excluded from the analysis because they did not meet either the case or referent selection criteria and would be likely to confuse the distinction between the two groups. This left a total of 12 referents.

\section{ASSESSMENT OF EXPOSURE}

Exposure to isocyanates was estimated in different ways for the two companies. At company A, exposure measurements by job category had been made by an occupational hygienist (JB) between 1979 and 1986 in the course of a separate study ${ }^{8}$ with continuous paper tape personal sampling monitors which were worn for a workshift. He used these records, together with data collected after 1986 on behalf of the company by other occupational hygiene consultants who used the same method, to estimate 8 hour time weighted average (TWA) and peak exposure to isocyanates for each subject based on job title and date.

Paper tape monitors provide a trace of TDI concentration against time. The area under the curve is a measure of the total dose ${ }^{9}$ and is divided by the duration of the shift to obtain the mean exposure ( 8 hour TWA). Peak exposure is defined as the highest concentration found on the trace. Paper tape monitors may underreact, and thus underestimate exposure to isocyanates, if relative humidity is less than $20 \%{ }^{9}$; however, the relative humidity was always greater than $40 \%$ when the readings used in this study were made. Paper tape monitors also underestimate peak exposures, ${ }^{9}$ and these estimates should be regarded as a 15 or 20 minute time weighted average rather than 
Table 1 Details of reported cases

\begin{tabular}{|c|c|c|c|c|c|c|c|c|c|}
\hline \multirow[b]{2}{*}{ Company } & \multirow{2}{*}{$\begin{array}{l}\text { Age } \\
\text { (onset) }\end{array}$} & \multirow[b]{2}{*}{ Sex } & \multirow{2}{*}{$\begin{array}{l}\text { Employment to } \\
\text { onset (months) }\end{array}$} & \multirow[b]{2}{*}{ Agent } & \multicolumn{3}{|l|}{ Exposure } & \multicolumn{2}{|l|}{ History at time of starting work } \\
\hline & & & & & $8 h T W A$ & $(p p b)$ & Peak $(p p b)$ & Atopy & Smoked \\
\hline \multirow[t]{28}{*}{ A } & 21 & M & $<1$ & TDI & 3.50 & & 30 & None & No \\
\hline & 42 & $\mathrm{M}$ & $<1$ & TDI & 1.13 & & 5 & None & Yes \\
\hline & 17 & $\mathrm{M}$ & $<1$ & TDI & 1.63 & & 30 & None & No \\
\hline & 36 & $\mathrm{M}$ & 1 & TDI & 2.25 & & 40 & Eczema & Yes \\
\hline & 35 & M & 1 & TDI & 1.63 & & 30 & None & Yes \\
\hline & 52 & M & 1 & TDI & 2.25 & & 40 & None & Yes \\
\hline & 15 & $\mathrm{M}$ & 1 & TDI & 0.63 & & 2 & Hay fever & No \\
\hline & 56 & $\mathrm{M}$ & 1 & TDI & 1.00 & & 12 & None & Yes \\
\hline & 32 & M & 2 & TDI & 1.63 & & 30 & None & Yes \\
\hline & 31 & $M$ & 3 & TDI & 2.63 & & 12 & None & No \\
\hline & 29 & M & 12 & TDI & 1.63 & & 30 & $\begin{array}{l}\text { Hay fever and childhood asthma } \\
\text { (last attack aged 14) }\end{array}$ & No \\
\hline & 43 & M & 18 & TDI & 0.38 & & 3 & None & No \\
\hline & 25 & M & 24 & TDI & 0.38 & & - & None & Yes \\
\hline & 44 & $\mathrm{~F}$ & 35 & TDI & 1.13 & & 5 & Eczema & Yes \\
\hline & 23 & M & 48 & TDI & 0.38 & & 3 & None & No \\
\hline & 22 & $M$ & 49 & TDI & 2.13 & & 40 & None & No \\
\hline & 32 & $\mathrm{~F}$ & 62 & TDI & 1.13 & & 5 & None & Yes \\
\hline & 35 & M & 77 & TDI & 1.25 & & 10 & None & No \\
\hline & 23 & $M$ & 84 & TDI & 2.63 & & 12 & None & Yes \\
\hline & 33 & M & 107 & TDI & 0.63 & & - & None & Yes \\
\hline & 33 & M & 134 & TDI & 1.13 & & 20 & Hay fever & No \\
\hline & 42 & $\mathrm{M}$ & 209 & TDI & 1.75 & & 6 & Hay fever & No \\
\hline & 49 & M & 228 & TDI & 0.44 & & 2 & None & Yes \\
\hline & 47 & $M$ & 276 & TDI & 3.13 & & 20 & Eczema & Yes \\
\hline & 41 & M & 30 & MDI & 1.50 & & 50 & None & Yes \\
\hline & 38 & $\mathrm{M}$ & 51 & MDI & 1.50 & & 50 & None & Yes \\
\hline & 36 & $\mathrm{~F}$ & 94 & MDI & 1.50 & & 50 & Hay fever & Yes \\
\hline & & & & & Samples & Exposure $\geqslant 2$ & Maximum (ppb) & & \\
\hline \multirow{8}{*}{ B } & 49 & $\mathrm{M}$ & 3 & $\mathrm{MDI}$ & $n_{4}$ & $\begin{array}{l}p p b(n) \\
2\end{array}$ & 8 & None & Yes \\
\hline & 33 & $\mathrm{M}$ & 14 & MDI & 3 & 1 & $\begin{array}{l}0 \\
2\end{array}$ & Wheezing on exposure to duck & No \\
\hline & & & & & & & 2 & feathers (last attack aged 25) & \\
\hline & 42 & M & 27 & MDI & 4 & 0 & $<2$ & None & Yes \\
\hline & 48 & $M$ & 63 & MDI & 39 & 4 & 6 & None & Yes \\
\hline & 51 & $\mathrm{M}$ & 72 & MDI & 8 & 2 & 2 & None & Yes \\
\hline & 47 & M & 123 & MDI & 13 & 1 & 3 & None & Yes \\
\hline & 49 & M & 183 & MDI & 13 & 0 & $<2$ & None & No \\
\hline
\end{tabular}

as a true value for an "instantaneous" peak concentration.

Exposures were estimated for the job each case was in when he or she developed asthma and for the job the matched control was in at that time, based on the paper tape monitoring records for those jobs as close as possible to the relevant period. When more than one measurement was available, the 8 hour TWA estimate was based on the mean value and the peak on the highest exposure recorded. Thus, the exposure measurements for company A were estimated from personal sampling of workers in specified jobs, but were not based on personal monitoring of the study subjects themselves. Time weighted average exposures were estimated for all 27 cases and 49 of the 51 referents, and peak exposures for 25 cases and 46 referents. All exposure estimates for study subjects were made without knowledge of identity or case-referent status.

At company $\mathrm{B}$ personal monitoring results from 1988 onwards were available. These time weighted average samples, of between 2 and 8 hours duration, but typically 4 hours, had been made with two different methods: the Marcali method $^{10}$ to the middle of 1990 , and high performance liquid chromatography ${ }^{11}$ thereafter. All exposure measurements before the date occupational asthma was diagnosed (for cases) or to the end of 1993 (for referents) were included. There were TWA exposure measurements recorded for all seven cases and for 11 of the 12 referents; short term peak exposure measurements were not available. For each subject, the proportion of measurements at or above the level of detection of the Marcali method $(2 \mathrm{ppb})$ and greater than $5 \mathrm{ppb}$ were calculated. Measurements below 2 ppb were treated as being zero.

For both cases and referents, occupational history, smoking history, and pre-employment history of asthma, hay fever, and eczema were extracted from medical surveillance and employment records. Also, at company B the medical records included information on spillages and accidents reported to the duty occupational health nurse and these were also extracted. It was not possible to remove details relating to occupational asthma from the records, but the data were compiled by an assistant unaware of the aims of the study.

\section{ANALYSIS}

The data from the two sites were analysed separately. The relative risk of asthma associated with concentration of exposure to isocyanates, smoking, and history of asthma, hay fever, and eczema were estimated. Also, the association between reported chemical accidents and asthma was examined for company B. Conditional logistic regression (Stata Version 5.0$)^{12}$ was used for the matched analysis of the data from company A. Eight hour TWA exposure to isocyanates was analysed in two ways: (a) as a binary variable, with the median concentration in the referent group as the cut off; and $(b)$ as a continuous variable expressed in $0.1 \mathrm{ppb}$ increments. 
Table 2 Characteristics of cases and referents by company

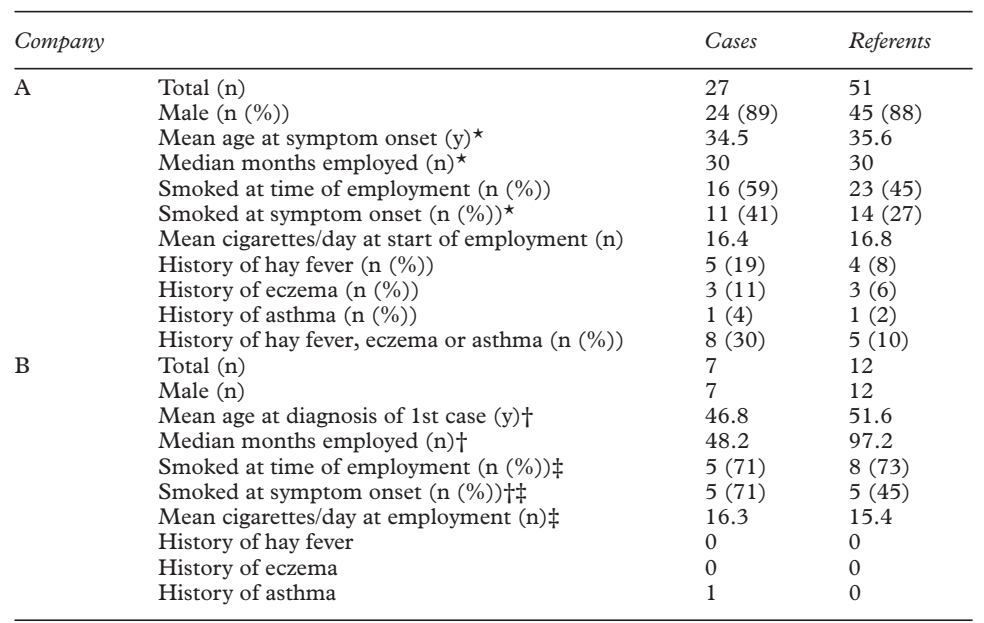

*At the time the matched case developed symptoms of asthma. tAt the time the first case of occupational asthma was diagnosed. $\ddagger$ Smoking information not available for one referent.

Table 3 Odds of occupational asthma at company A (unadjusted estimates)

\begin{tabular}{llll}
\hline & Odds ratio & 95\% CI & p Value \\
\hline Isocyanate exposure (for 0.1 ppb increase in 8 h TWA) & 1.08 & 1.00 to 1.17 & 0.06 \\
Smoking at time of employment & 2.1 & 0.78 to 5.84 & 0.14 \\
Smoking at symptom onset & 2.1 & 0.68 to 6.74 & 0.19 \\
History of hay fever & 2.7 & 0.62 to 11.5 & 0.19 \\
History of eczema & 2.0 & 0.40 to 9.91 & 0.40 \\
History of asthma & 2.0 & 0.13 to 32.0 & 0.62 \\
History of either hay fever, eczema, or asthma & 3.5 & 1.03 to 11.7 & 0.04 \\
\hline
\end{tabular}

Table 4 Adjusted odds ratio estimates for occupational asthma at company $A$ (adjusted for the three risk factors listed)

\begin{tabular}{llll}
\hline & Odds ratio & $95 \%$ CI & p Value \\
\hline Isocyanate exposure (for 0.1 ppb increase in 8 h TWA) & 1.07 & 0.99 to 1.16 & 0.10 \\
Smoking at time of employment & 2.4 & 0.84 to 7.4 & 0.11 \\
History of either hay fever, eczema, or asthma & 3.4 & 0.85 to 13.4 & 0.08 \\
\hline
\end{tabular}

\section{Results}

Details of the cases from the two sites are shown in table 1 , and the characteristics of cases and referents in table 2 . The matching at company A was close, but at company B referents were somewhat older and had worked at the plant for longer than the cases.

At both sites, cigarette smoking was more common at the time of employment than later when the cases of asthma developed. The proportion of cases from company A who smoked was greater than referents at both points in time. At company B, there was no difference in smoking at the time of employment. However, by the time the first case was diagnosed three of the referents but none of the cases had given up smoking, thus a higher proportion of cases than referents smoked at that time. There was no difference between cases and referents in the number of cigarettes smoked at either site.

At company A, a history at pre-employment screening of hay fever, eczema, or asthma seemed to be more common in cases than referents. None of the subjects at company B gave a history of atopic symptoms at the time of employment, apart from one (a case) who complained of wheezing on exposure to feathers.

COMPANY A

Estimated peak exposures ranged between 1 and $50 \mathrm{ppb}$. No difference was found between the 27 cases and 51 matched referents in estimated peak exposure (means $21.5 \mathrm{ppb}$ and $22.5 \mathrm{ppb}$, respectively). In 31 subjects (44\%) peak exposures were estimated to be greater than $20 \mathrm{ppb}$; this proportion was the same for both cases and referents.

The highest 8 hour TWA exposure to isocyanates among the study subjects was estimated to be $3.5 \mathrm{ppb}$; the mean for the cases $(1.5 \mathrm{ppb}$, $95 \%$ confidence interval (95\% CI) 1.2 to 1.8 ) was slightly higher than for the referents $(1.2$ ppb, $95 \%$ CI 1.0 to 1.4$)$. The odds of occupational asthma for those for whom estimated exposure to isocyanates was greater than the median concentration for the control group (1.125 ppb) was 3.2 times the odds for those exposed to lower concentrations (95\% CI 0.96 to $10.6 ; \mathrm{p}=0.06$ ).

The relations between occupational asthma and estimated daily exposure to isocyanates, smoking, and history of hay fever, eczema, and asthma are shown in table 3. No single factor was associated with a significantly increased risk, but odds ratios (ORs) were raised for all risk factors examined. The odds of occupational asthma increased by $8 \%$ for each $0.1 \mathrm{ppb}$ increase in 8 hour time weighted average exposure $(p=0.06)$. The risks associated with smoking at the time of employment and at the time of onset of symptoms were similar. Those with a history of at least one of the three atopic illnesses were at 3.5-fold increased risk of occupational asthma $(\mathrm{p}=0.04)$. The multivariate model had little impact on the estimates of relative risk (table 4 ).

In $11(41 \%)$ of the cases, symptoms began in the first year of employment at the plant and nine occurred within 3 months. The difference between cases and referents in mean 8 hour TWA exposure was most pronounced in these 11 matched sets (1.8 ppb for the cases and 1.3 ppb for referents). The matched analysis was repeated separately for the sets in which the case developed asthma within a year of employment and those in which asthma developed later (table 5). The reduction in sample size also reduced the power, but the effects of smoking and history of atopic illness were similar in the two groups. However, there seemed to be no association between current exposure to isocyanates and the development of asthma more than 1 year from first employment.

To explore the possibility that earlier exposures might be relevant to the development of asthma more than 1 year after first employment, the analysis was repeated with four other measures of exposure to isocyanates. These were: (a) TWA exposure to isocyanates for all jobs since first employment at the company; (b) the TWA exposure in the first job for each subject; (c) the highest estimated TWA exposure of all the jobs the subject did in the company; and (d) the highest estimated peak exposure. The results with each of these were very similar to those obtained with exposure to isocyanates at the time of onset of symptoms. Overall, higher exposures seemed to be associated with increased risk of disease, but this was limited to those cases which occurred in the first year of employment. None of the measures of expo- 
Table 5 Odds of occupational asthma at company A by duration from employment to symptoms (unadjusted estimates)

\begin{tabular}{|c|c|c|c|c|c|c|}
\hline & \multicolumn{3}{|c|}{ Asthma $\leqslant 1 y$} & \multicolumn{3}{|c|}{ Asthma $>1 y$} \\
\hline & Odds ratio & $95 \% C I$ & $p$ Value & Odds ratio & $95 \% C I$ & $p$ Value \\
\hline $8 \mathrm{~h}$ TWA isocyanate exposure (for $0.1 \mathrm{ppb}$ increase) & 1.5 & 0.82 to 2.7 & 0.18 & 1.04 & 0.95 to 1.13 & 0.41 \\
\hline Smoking at employment & 2.4 & 0.38 to 15.0 & 0.36 & 2.0 & 0.60 to 6.78 & 0.25 \\
\hline History of hay fever, eczema, or asthma & 2.6 & 0.43 to 16.0 & 0.29 & 4.3 & 0.60 to 22.8 & 0.08 \\
\hline
\end{tabular}

sure to isocyanates was associated with disease which developed after 1 year. Estimated highest peak exposures were similar for cases and referents.

\section{COMPANY B}

The referent group had worked at the plant for longer than the cases (table 2) and also had more personal monitoring samples recorded (median 13.5 for referents and eight for cases). There was, however, no difference between cases and referents in the proportion who had reported an accident with isocyanates to the occupational health department (five of 11 referents and three of seven cases)

Of the 269 TWA samples of exposure to isocyanates, $90 \%$ were less than $2 \mathrm{ppb}, 169$ of 185 (91.4\%) for referents, and 74 of $84(88 \%)$ for cases. The mean and median exposures for both cases and referents were below the level of detection, and the median of the highest concentration recorded for each subject was the same for both groups ( $3 \mathrm{ppb})$. There was, however, some suggestion from the data that the cases may have been exposed to higher concentrations of isocyanates than the referent group. The proportion of measurements greater than or equal to $2 \mathrm{ppb}$ was 0.09 for referents and 0.18 for cases, and the proportions greater than $5 \mathrm{ppb}$ were 0.004 and 0.09 , respectively. Three of the seven cases had at least one TWA exposure measurement greater than $5 \mathrm{ppb}$ compared with only one of the 11 referents (OR 7.5; $\mathrm{p}=0.09)$.

Smoking at the time the first case was diagnosed increased the odds of occupational asthma threefold; however, the probability that the difference was due to chance was high $(\mathrm{p}=0.28)$.

\section{Discussion}

The maximum exposure limits in the United Kingdom for airborne concentrations of free isocyanate groups are set at $0.02 \mathrm{mg}(-$ $\mathrm{NCO}) \cdot \mathrm{m}^{-3}$ for 8 hour TWA exposure, equivalent to $5.7 \mathrm{ppb}$, and a 15 minute TWA of 0.07 $\mathrm{mg}(-\mathrm{NCO}) \cdot \mathrm{m}^{-3}$, equivalent to $20 \mathrm{ppb} \cdot{ }^{13}$ Apart from a few samples at company $B$, exposures at both sites seem to have been within the 8 hour TWA limit, but the 34 cases of occupational asthma described here occurred, notwithstanding. Bernstein et al also found that when exposures were kept below 5 ppb, occupational asthma was rare but a few cases were detected. ${ }^{14}$

Despite small numbers and the different methods used to investigate the two groups of cases, at both sites studied workers with occupational asthma diagnosed by a physician had experienced higher exposure to isocyanates than referent subjects working in the same area. At company A, the higher the exposure, the greater the risk of occupational asthma, with the odds increased by 1.08 , or $8 \%$, for each $0.1 \mathrm{ppb}$ increment in 8 hour TWA exposure. At company B, a higher proportion of subjects with occupational asthma than referents had recorded personal TWA exposures of over $5 \mathrm{ppb}$. The findings for company $\mathrm{B}$ are compatible with those of Tarlo et $a l^{15}$ who undertook the only other study known to us which considered the issue of quantitative exposure-response in isocyanate asthma. In companies that had had isocyanate concentrations measured by the Ontario Ministry of Labour, those in which there were workers with a successful claim for occupational asthma were more likely to have had an ambient isocyanate concentration of $5 \mathrm{ppb}$ or more recorded than those companies without successful claims.

Eleven of the cases from company A and two from company $\mathrm{B}$ developed occupational asthma within a year of first exposure. This proportion $(38 \%)$ is similar to that described by Chan-Yeung and Malo in their case series of occupational asthma due to isocyanates. ${ }^{16}$ The difference in exposure between cases and referents at company A was limited to the matched groups in which the case developed asthma within a year of employment. There was no indication of earlier exposure to isocyanates in these cases; two of the cases were in their first job and the previous jobs listed by the rest were judged unlikely to have involved isocyanates. There was also no evidence that the cases who developed asthma at least 1 year after first employment had experienced higher concentrations of exposure to isocyanates than the referent group. These findings require corroboration, but if confirmed, suggest that the aetiology of asthma due to isocyanates which occurs soon after exposure may differ from asthma which develops after longer periods of employment.

Intermittent high exposures to isocyanates from accidental spills and splashes have been associated with respiratory sensitisation. ${ }^{17}$ Information on incidents was available for company B, but there was no difference found between cases and referents in numbers of reported chemical accidents. However, because of the small numbers at company B, the lack of evidence does not preclude such an association. There was no information available on incidents at company $\mathrm{A}$, but it is thought that the systems of work adopted made spillages less likely. However, peaks routinely occur as part of the manufacturing process. Peak exposures were estimated according to occupation for the subjects at company A, but no relation was detected between estimated peak exposure and 
asthma. It should be noted, however, that the peak (15 minute TWA) exposures were estimated to be in excess of the current United Kingdom limit for about half of all cases and referents.

Smoking has been shown to increase the risk of allergy in workers exposed to several agents including platinum salts, ${ }^{18}$ tetrachlorophthalic anhydride, ${ }^{19}$ and snow crabs. $^{20}$ Based on limited evidence, mainly from case series, isocyanate asthma is generally thought not to be associated with smoking, ${ }^{21}$ indeed, some authors think that smoking can be protective. ${ }^{22}$ We found that smoking at the time asthma was first noted was associated with an increased risk of occupational asthma in both companies although in neither was the increase significant. Smoking at the time of employment was also associated with the development of asthma at company A but not company B. This may be due to the fact that the prevalence of smoking declined over time in both companies, and on average the referent group at company B was employed at the plant earlier than the cases.

The apparent association between atopy and asthma due to isocyanates was one of the more surprising findings of this study. Direct information on atopy from skin prick tests was not available, but pre-employment screening at both sites included questions on hay fever, eczema, and asthma, which provided an indirect indicator of possible atopy. As Slovak and Hill have pointed out, ${ }^{23}$ classification based on history may not identify as atopic the same people as skin prick testing, but although imperfect, history provides a reasonable marker for atopy. In the population of laboratory workers studied by Slovak and Hill, 72\% of subjects classified by personal history reacted to skin prick tests with a standard mixture of allergens. We found that at company A, a history of either hay fever, eczema, or asthma at the time of employment tripled the risk of developing occupational asthma. This was not found at company $\mathrm{B}$, but the very low prevalence of atopic illness among the study subjects, which may reflect pre-employment screening practices, prevented exploration of the association in that population.

Previous research has shown atopy to be a risk factor for occupational asthma due to agents that induce specific IgE antibodies. ${ }^{24}$ These are mainly high molecular weight substances such as latex, laboratory animal allergens, and enzymes. Specific IgE antibodies are only found in a small proportion of cases of asthma due to isocyanates and the pathological mechanism in most cases is unclear. ${ }^{25}$ Atopy has not previously been associated with asthma due to low molecular weight agents - such as isocyanates. It is possible however, that the association with atopy found in this study was due to the inclusion of some cases with asthma mediated by IgE.

A limitation of this study is that person specific exposure measurements were not available at company A and so exposures were estimated from job title and date. Referents were closely matched to cases and selected from the same work areas in an attempt to ensure a similar level of surveillance and a similar chance that occupational asthma would be diagnosed if it occurred. This was done to minimise the risk of selection bias, a common problem in casecontrol studies. The close matching, in conjunction with the relatively insensitive method of exposure measurement, is likely to have reduced our ability to detect differences between cases and referents; despite this a difference was found.

The risks associated with smoking and history of hay fever, eczema, or asthma were at least as strong as that associated with exposure to isocyanate at company $\mathrm{A}$, but it must be remembered that they were based on personal information for each subject whereas the exposure to isocyanates was not. This is likely to have weakened the observed association with exposure to isocyanates and made the other associations examined seem relatively stronger.

Finally, although it is most probable that these cases are due to exposure to isocyanates, it should be recognised that other chemical species, in particular, amines, which are used as catalysts in the manufacture of polyurethane foams, have been reported as causing respiratory symptoms and their involvement cannot be wholly excluded.

We thank the SWORD project team and the occupational health staff of the participating companies for their help and support.

1 Ross DJ, Keynes HL, McDonald. SWORD '96: surveillance of work-related and occupational respiratory disease in the of work-related and occupational

UK. Occup Med 1997;47:377-81.
2 Health and Safety Commission. Health and safety statistics 1997-8. London: HSE Books, 1998

3 Lozewicz BK, Assoufi BK, Hawkins R, et al. Outcome of asthma induced by isocyanates. Br F Dis Chest 1987;81:4-22.

4 Mapp CE, Paolo CC, de Marzo N, et al. Persistent asthma due to isocyanates. Am Rev Respir Dis 1987;137:1326-9.

5 Pisati G, Baruffini A, Zedda S. Toluene diisocyanate induced asthma: outcome according to persistence or cessation of exposure. Br F Ind Med 1993;50:60-4.

6 Gannon PFG, Weir DC, Robertson AS, et al. Health, employment, and financial outcomes in workers with occupational asthma. Br F Ind Med 1993;50:491-6.

7 Cannon J, Cullinan P, Newman Taylor A. Consequences of Cannon J, Cullinan P, Newman Taylor A. Co

8 Clark RL, Bugler J, McDermott M, et al. An epidemiology study of lung function changes of toluene diisocyanate foam workers in the United Kingdom. Int Arch Occup foam workers in the United Kin
Environ Health 1998;71:169-79.

9 Dharmarajan V, Rando RJ. Critical evaluation of continuous monitors for toluene diisocyanate. Am Ind Hyg Assoc 7 1980;41:869-78

10 Health and Safety Executive. Methods for the determination of hazardous substances MDHS 49: aromatic isocyanates in air: field method using acid hydrolysis, diazotisation, and coupling with N-2-aminoethyl-1-naphthylamine. London: The Stationery Office, 1985.

11 Health and Safety Executive. Methods for the determination of hazardous substances MDHS 25/2: organic isocyanates in air: laboratory method using 1-(2-methoxyphenyl) piperazine solution and high performance liquid chromatography. London: tion and high performance liquid

12 StataCorp. Stata statistical software: release 5.0. College Station, TX: Stata Corporation, 1997.

13 Health and Safety Executive. Guidance note EH16: isocyanates: health hazards and precautionary measures. London: HSE Books , 1997

14 Bernstein DI, Korbee L, Stauder T, et al. The low prevalence of occupational asthma and antibodydependent sensitization to diphenylmethane diisocyanate in a plant engineered for minimal exposure to diisocyanates. F Allergy Clin Immunol 1993;92:387-96.

15 Tarlo SM, Liss GM, Dias C, et al. Assessment of the relationship between isocyanate exposure levels and occupational asthma. Am F Ind Med 1997;35:517-21.

16 Chan-Yeung M, Malo JL. Natural history of occupational asthma. In: Bernstein IL, Chan-Yeung M, Malo JL, eds. asthma. In: Bernstein IL, Chan-Yeung M, Malo JL, eds. Asthma in the

$17 \mathrm{Karol} \mathrm{MH}$. Survey of industrial workers for antibodies to toluene diisocyanate. F Occup Med 1981;23:741-7. 
18 Venables KM, Dally MB, Nunn AJ, et al. Smoking and occupational allergy in workers in a platinum refinery. $B M \mathcal{F}$ occupational allergy

19 Venables KM, Topping MD, Howe W, et al. Interaction of smoking and atopy in producing specific IgE antibody against a hapten protein conjugate. BMF 1985;290:201-4.

20 Cartier A, Malo JL, Forest F, et al. Occupational asthma in snow-crab processing workers. F Allergy Clin Immunol 1984;74:261-9

21 Mapp CE, Boschetto P, Dal Vecchio L, et al. Occupational asthma due to isocyanates. Eur Respir f 1988;1:273-9.
22 Chan-Yeung M. Occupational asthma. Chest 1990;98:148S$156 \mathrm{~S}$.

23 Slovak AJM, Hill RN. Does atopy have any predictive value for laboratory animal allergy? A comparison of different concepts of atopy. Br F Ind Med 1987;44:129-32.

24 Cullinan P, Newman Taylor AJ. Aetiology of occupational asthma. Clin Exp Allergy 1997;27(suppl 1):41-6.

25 Vandenplas O, Malo JL, Saetta M, et al. Occupational asthma and extrinsic alveolitis due to isocyanates: current asthma and extrinsic alveolitis due to isocyanates: curr
status and perspectives. Br f Ind Med 1993;50:213-28.

\section{Open reviewing}

Many journals, including the BMJ, have moved to a system of open reviewing, whereby authors know the names of reviewers of their papers. Research has shown that named reviews, although not of better quality than anonymous reviews, are not of worse quality either. Therefore in the interests of transparency, it seems fair to let authors know who has reviewed their paper. At Occupational and Environmental Medicine we have considered the issue carefully. There are some concerns that reviewers, especially those who are more junior, might feel intimidated and not wish to make negative comments about papers submitted by senior people in the field. On the other hand, some reviewers might hide behind the cloak of anonymity to make unfair criticisms so as to reduce the chances of publication by rivals. We have decided to introduce initially a system of open reviewing if the reviewers agree explicitly. So when a reviewer is sent a paper, he or she is asked to indicate whether we can disclose their name or not when sending the authors their comments. We will be monitoring this to see how many of our reviewers are happy to be named. If it is most of them, we will move to a system of open reviewing as the norm, with a possible "opt out" clause for reviewers. 